\title{
Countdown to 2030: tracking progress towards universal coverage for reproductive, maternal, newborn and child health
}

Countdown to 2030 Collaboration

\begin{abstract}
Building upon the successes of Countdown to 2015, the Countdown to 2030 aims to support the monitoring and measurement of women's, children's and adolescents' health in the 81 countries that account for $95 \%$ of maternal and $90 \%$ of all child deaths in the world.

To reach the Sustainable Development Goal targets by 2030, the rate of decline in maternal and child mortality and stillbirths, as well prevalence of stunting among children under five years of age, needs to accelerate considerably compared to progress since 2000 . Such accelerations are only possible with a rapid scale-up of effective interventions to all population groups within countries, particularly in the highest mortality countries and those affected by conflict, supported by improvements in underlying socio-economic conditions including women's empowerment.

Three main conclusions emerge from our analysis of intervention coverage, equity and drivers of reproductive, maternal, newborn and child health (RMNCH) in the 81 Countdown countries. First, even though strong progress in the coverage of many essential $\mathrm{RMNCH}$ interventions was made during the past decade, many countries are still a long way from universal coverage for most essential interventions. Moreover, there is growing evidence of the limited quality of services, limiting the potential impact on RMNCH outcomes. Second, within-country inequalities in intervention coverage are reducing in most countries, to almost none in a few countries, but the pace is too slow. Third, health sector (weak country health systems) and non-health sector drivers (e.g. conflict settings) are major impediments to reaching all with quality services.

Although more data on RMNCH interventions are available now, there are still major data gaps that preclude the use of evidence to drive decision-making and accountability. Countdown to 2030 is investing in improving measurement in several areas, such as quality of care and effective coverage, nutrition programs, adolescent health, early childhood development and evidence for conflict settings, and is prioritizing its regional networks to enhance local analytical capacity and evidence for RMNCH.
\end{abstract}




\section{Key messages}

- The 81 Countdown countries have made progress but are still a long way from universal coverage for most essential interventions for RMNCH and nutrition.

- Major investments are needed to achieve the RMNCH-related SDG targets, which must be guided by reliable data on intervention coverage and quality of care for all inequality dimensions and in conflict settings.

- To address the broader SDG agenda, measurement improvements should focus on strengthening vital statistics, understanding drivers of coverage change, and better data on early childhood development and adolescent health.

- Strengthening country analytical capacity, a priority for the Countdown to 2030 , is crucial to improve monitoring and accountability for women's, children's and adolescents' health. 


\section{Introduction}

The Millennium Development Goals (MDGs) era was characterized by an unprecedented decline in child and maternal mortality during 2000-2015, even though the mortality targets were not met by most countries. ${ }^{1}{ }^{3}{ }^{4}$ Concerted action around the MDGs - a limited number of time-bound, measurable and easy to communicate goals - plus major increases in funding for health, including for reproductive, maternal, newborn, and child health and nutrition (RMNCH), and scale-up of existing and new interventions are considered critical factors that contributed to this decline. ${ }^{5}{ }^{7}$ Progress was also driven by reductions in fertility and significant improvements in underlying determinants such as poverty and adolescent girls' education. ${ }^{81} 1{ }^{11}$ Health was prominently featured in three of the MDGs, two of which were specific to RMNCH. The 2030 agenda for sustainable development, adopted by the UN General Assembly in September 2015, is much broader than the MDG framework. ${ }^{12} \mathrm{RMNCH}$ is addressed in three of the 13 targets of the sustainable development goal for health (SDG 3), and in several targets in the other 16 SDGs. The need to reduce persistent inequalities in RMNCH between and within countries is explicitly acknowledged, as is the aim of reaching all with effective and affordable interventions.

The Global Strategy for Women's, Children's and Adolescents' Health (2016-2030) in support of Every Woman Every Child was developed to translate the SDG agenda into a comprehensive "survive, thrive, transform" framework for improving women's, children's and adolescents' health through an inclusive and multi-sectoral approach. ${ }^{13}{ }^{14}$ The Global Financing Facility (GFF) for women, children and adolescents was also launched in 2015 to ensure scaled and sustained financing through country-driven investment cases. ${ }^{15}$

Countdown to 2030 for Women's, Children's and Adolescents' Health (Countdown) is a multiinstitutional network of academics from institutions around the world and representatives from United Nations (UN) agencies and civil society that builds upon the successes of Countdown to $2015 .{ }^{6}{ }^{16} \mathrm{~A}$ key output of Countdown is a regular review of progress towards RMNCH targets in the 81 countries with the highest burden of maternal, neonatal and child mortality. Based on global estimates for population and mortality, the 81 countries accounted for nearly half (47\%) of the world's population, nearly twothirds (64\%) of all births in the world, and $90 \%$ of all child deaths and $95 \%$ of all maternal deaths in 2015. ${ }^{17} 1,2$ This paper analyzes progress in improving intervention coverage, equity and drivers of RMNCH in the Countdown countries, summarizes key gains, signals areas for further action, and shows how Countdown priorities are evolving in response to the SDGs and universal health coverage (UHC) challenge.

The Countdown list of priority countries, core indicators and equity dimensions were revised to address the SDG agenda, and to take into account country progress during the MDG era (Appendix A). Areas of expansion from Countdown to 2015 include nutrition, quality of care, adolescent girls' reproductive health, and RMNCH in conflict settings.

\section{Maternal, neonatal and child survival}

Under-five and neonatal mortality in the 81 countries declined rapidly during 2000-2015 to 59 and 24 per 1,000 live births respectively in $2015 .{ }^{18}$ A major acceleration of the mortality decline is, however, required for countries to reach the SDG under-five and neonatal mortality targets of 25 and 12 per 1,000 live births, respectively especially among the highest mortality countries. The average annual rates of 
decline in the 50 highest mortality Countdown countries will need to almost double for under-five mortality and more than double for neonatal mortality during 2015-2030, compared with 2000-2015 (Figure 1). A similar acceleration of the decline is required for stillbirth rates to achieve the global Every Newborn Action Plan for 2030 target of 12 per 1,000 births or fewer. ${ }^{19}{ }^{20}$ Reaching the global maternal mortality SDG target of less than 70 maternal deaths per 100,000 live births (at the country level, the target is two-thirds reduction from 2010 baseline and no country higher than 140 by 2030) requires an equally large acceleration of the annual rate of decline. ${ }^{21}$

It is too early to assess if the pace of mortality decline is changing post-2015. Since the final MDG assessment of achievements in September 2015, just over one-third of the 81 countries published new child mortality data, mostly from retrospective household surveys which provide data for the years prior to 2015 . The predicted estimates for 2016 do not show a major change in the annual rate of reduction, ${ }^{22}$ but a comprehensive account of trends in the initial SDG years will only be possible in a few years' time.

The lack of data on causes of child mortality in the 81 countries is striking. Only five countries were considered to have good quality cause of death data from national civil registration systems. ${ }^{23}$ For 2010 2014, 14 countries had national data on causes of death in childhood, mostly from verbal autopsy studies, another 20 had subnational information only and the remaining 47 countries had no information for 2010-2014. Model-based estimates suggest that during 2000-2015, under-five mortality due to vaccine-preventable diseases such as measles declined the most, and deaths due to diarrhoea, pneumonia and malaria also more than halved in the Countdown countries. ${ }^{23}{ }^{24}$ The declines in mortality due to neonatal causes were less pronounced. By 2015, the leading causes of under-five deaths were estimated to be preterm birth complications (17\%), pneumonia (13\%), intrapartum-related events (11\%) and diarrhoea (10\%). Data on maternal causes of death are even sparser than for child mortality. Global estimates suggest that haemorrhage, hypertensive disorders and sepsis are the three leading causes in high mortality countries, with some variations in the proportion due to these causes by region. ${ }^{25} 26$

\section{Nutritional status}

Undernutrition - including foetal growth restriction, stunting and wasting, and micronutrient deficiencies such as vitamin A, iodine, iron and zinc - along with sub-optimal breastfeeding has been estimated to contribute to $45 \%$ of deaths in children under the age of five years in 2011 , and to poor childhood development. ${ }^{27} 28$ Levels of stunting in children under five years have dropped considerably in the past decade ${ }^{29}$, but about half of Countdown countries with available data still have a national prevalence of $30 \%$ or higher. We used multilevel models to ascertain long term trends in stunting in children under 5 years and for the $\mathrm{CCl}$ among the poorest and richest quintile in a pooled analysis of countries (Appendix B and C). The decline in stunting rates accelerated around 2005 among children in both richest and poorest households, based on data from 53 Countdown countries (Figure 2). There is, however, no evidence of a reduction in the absolute gap between the rich and poor.

Fifteen countries had a national prevalence of wasting exceeding $10 \%$. The list includes fragile states such as South Sudan, Chad, Timor-Leste, Pakistan and Yemen. Wasting is consistently higher among children living in poorer households. At the same time, many Countdown countries are facing increases in overweight and obesity among women and children. Although child overweight does not yet appear to be a widespread problem, five out of the 56 countries with available data had a prevalence of over $10 \%$. Among women aged 20 and over, median prevalences of underweight $\left(\mathrm{BMI}<18.5 \mathrm{~kg} / \mathrm{m}^{2}\right)$ and obesity $(\mathrm{BMI}>30)$ for the 79 countries with available data were $8 \%$ (range 1-24\%) and $14 \%$ (range 5- 
41\%) respectively, with several countries facing high levels at both ends of the anthropometric status spectrum.

\section{Coverage}

Household surveys are the main source of data used to compare coverage trends and inequalities between and within countries. Data availability for Countdown coverage indicators improved considerably since 2005, benefitting from the increased frequency of surveys conducted in the context of international household survey programmes (USAID-supported Demographic and Health Surveys (DHS) and UNICEF supported Multiple Indicator Cluster Surveys (MICS)). We have previously reported on Countdown's data sources and methods (Appendix A). ${ }^{6}$

The analyses focus on assessing progress and inequalities across the RMNCH continuum of care. They include the robust composite coverage index $(\mathrm{CCl}) .{ }^{30}$ The $\mathrm{CCl}$ is a weighted average of the coverage of eight interventions along four stages of the RMNCH continuum of care: reproductive health (family planning), maternal and newborn care (antenatal care and skilled birth attendant), immunization (BCG, DTP3 and measles vaccinations) and management of child illness (care seeking for suspected pneumonia and diarrhoea) (Appendix B). All coverage and equity computations were done in Stata version 15. Results are based on analysis of all available data for the 81 Countdown countries and country summary measures are presented without population weighting, unless stated otherwise.

National coverage rates in the Countdown countries of many essential interventions across the continuum of care - from pregnancy prevention and planning, pregnancy, birth, postnatal, infancy, childhood to environment -are still a long way from universality (Figure 3). Countries in West and Central Africa are prominent among those with the lowest levels of coverage for almost all interventions (Table 1). Median coverage is still below $50 \%$ for postnatal care for babies (36\%), exclusive breastfeeding $(47 \%)$, treatment of diarrhea with ORS (43\%), population using basic sanitation services (44\%), and demand for family planning satisfied with modern methods (48\%). Only immunization indicators and continued breastfeeding at $12-15$ months have median coverage levels above $80 \%$. These figures translate into large numbers of women and children not reached with essential services (Panel 1).

Coverage increased for most interventions, most steeply for interventions that were relatively new, such as new vaccines and pregnant women living with HIV receiving antiretroviral therapy. Notable is the progress in skilled birth attendant rates after years of stagnation in many countries, presenting a major opportunity to reduce intrapartum stillbirth and neonatal mortality rates (Table 2). Several malaria intervention indicators, also showed major increases (e.g. use of insecticide treated bed nets) (Appendix $D$ includes the list of Countdown countries considered malaria endemic and current coverage levels of the malaria interventions in these countries). Less progress was made in coverage of family planning and antenatal care (four or more visits), infant and young child feeding behaviors, and coverage of treatment of childhood illnesses and population using basic sanitation services.

Many coverage indicators tracked by Countdown, and included in the Every Woman Every Child Global Strategy and SDG frameworks, capture information on contact with health services and do not take into account the quality of services received. There is increasing evidence about major gaps in the quality of care that affect the extent to which interventions can positively impact health (Panel 2).

\section{Equity}


Progress towards universal coverage must be assessed not only in terms of national averages, but also on how well such gains benefit all population groups. Survey data were used to classify households into wealth quintiles, based on the ownership of household assets and on housing characteristics. ${ }^{31}$ The slope index of inequality, which measures the difference in coverage between the richest and poorest extremes of the wealth scale while taking into account the full wealth distribution, was used to summarize inequality patterns. ${ }^{32}$ When comparing wealth-related inequalities between countries it must be kept in mind that the wealth quintiles are country-specific and vary according to context, representing relative socioeconomic position for a given country at a certain time, rather than absolute wealth.

Among 65 Countdown countries with data from 2005, marked differences in the $\mathrm{CCl}$ are observed by household wealth with half the poorest quintiles having a $\mathrm{CCl}$ below $50 \%$, compared to only $2 \%$ for the wealthiest quintile (Table 3). Differences by urban versus rural residence and mother's level of education are also large. Only Panama and Swaziland had coverage of $80 \%$ or higher in more than half of the subgroups with data. Fifty of the 62 countries with data on these equity dimensions did not have a single subgroup with $80 \%$ or higher coverage.

Countries differ considerably according to the magnitude of wealth-related inequalities in the $\mathrm{CCl}$ (Figure 4). Nigeria was the most unequal country, with a slope index of inequality showing a 64 percentage-point difference between the top and bottom extremes of wealth, followed by Angola with an index of 59. The slope index was positive - meaning higher coverage among the rich than the poor in all countries except for Turkmenistan. In 30 countries, the slope index was greater than 20 percentage points. Nine countries showed little inequality, with an index below 10 percent points. Chad was the only country where the $\mathrm{CCl}$ was below $50 \%$ in even the richest quintile.

The inequalities vary for the eight coverage indicators included in the $\mathrm{CCI}$ (Appendix $\mathrm{E}$ ). Gaps tend to be smaller for the use of oral rehydration solution for diarrhea management and for immunization coverage, compared to coverage of skilled birth attendant or antenatal care (four or more visits). These results confirm earlier findings highlighted by Countdown: interventions that can be delivered at community level tend to be more equitable than those requiring access to fixed and well-equipped health facilities. ${ }^{6}$

Other dimensions of inequality need to be tracked to best assess progress in reaching all population groups, such as ethnicity, geographic regions or women's age. The initial results of the work of the Countdown regional initiative in Latin America and the Caribbean show that coverage of virtually all RMNCH interventions except for the infant feeding behaviors were lower in indigenous compared to non-indigenous populations. Among adolescent girls aged $15-17$ years, $48 \%$ had a $\mathrm{CCl}$ below $50 \%$ (Table 3 ), compared to $21 \%$ of women $20-49$ years. Low coverage levels among adolescent girls in need of family planning contributed to the low $\mathrm{CCl}$, more so than coverage of antenatal care and skilled birth attendance. Subnational analyses focused on geographical areas are particularly relevant as they can help program managers target interventions along administrative divisions within a country. Keeping in mind that variation in the number of subnational units limits the comparability of regional inequalities between countries, Figure 5 shows the wide range of geographic disparities that are present within selected countries.

Socioeconomic and urban-rural gaps in coverage are being reduced in many Countdown countries, but there is still a long way to go before universal coverage is achieved (Figure 6). For instance, progress in reaching rural women and children with needed interventions was faster than progress for their urban counterparts in both low-income (annual $\mathrm{CCl}$ increases of 1.1 and 0.6 percent points, respectively) and middle-income Countdown countries ( 0.9 and 0.5 percent points, respectively). 


\section{Drivers}

The SDGs stress the need to address the drivers or determinants of women's, children's and adolescents' health. This includes health system as well as socioeconomic, cultural, political and environmental factors. For some key drivers, such as women's empowerment, a positive association with the coverage of RMNCH interventions has been demonstrated. ${ }^{33}$ The impact of conflict, both during and after, on women's and children's health can be devastating (Panel 3).

Countdown reports on a set of 17 indicators related to four main drivers of coverage of effective interventions: legislative commitments, governance processes, financial investments and health service delivery inputs. There are major legislative gaps: $68 \%$ of the 74 Countdown countries with available data have no legislation on maternity protection ${ }^{34}, 29 \%$ the 79 countries with data have none on adoption of legislation to regulate the marketing of breastmilk substitutes, $53 \%$ of the 70 countries with recent data have no legislation allowing adolescents access to family planning without spousal or parental consent, and $38 \%$ of the 81 countries have no legislation on fortification of at least one staple food (wheat, rice, maize). ${ }^{35}$ One country fully restricts abortion and 31 countries only allow abortion if the woman's life is at risk. ${ }^{36}$ Globally, unsafe abortion rates have been found to be higher in countries with highly restrictive abortion laws compared to those with less restrictive laws. ${ }^{37}$

Policy analysis entails moving beyond assessing the presence or absence of a policy. ${ }^{38}$ Understanding the political economy of how policy issues are framed, who are the actors that support or block a policy, what organisational mechanisms support the development, review or implementation of a policy, and whether funding and other service delivery inputs support sustained policy operationalisation are critical to supporting country efforts to address $\mathrm{RMNCH}^{39}$ This helps explain why, for instance, maternal health or integrated community case management became a priority for some countries but not others. ${ }^{40} 41$ Countdown reports on indicators concerned with governance processes such as the presence of costed national plans for maternal, newborn and child health (present in $49 \%$ of the 71 countries with data), maternal death surveillance and response, and civil society involvement in national planning and review processes,${ }^{42}$ but often more in-depth information is required to gauge policy implementation.

Financial monitoring includes official development assistance (ODA), flows from private foundations, domestic spending on $\mathrm{RMNCH}$ and the affordability of RMNCH services. An assessment of ODA and private foundation flows for the period 2003-2013 for Countdown to 2015 countries showed that funding to RMNCH increased more than threefold, similar to the health sector overall. ${ }^{43}$ Child health received the largest increase in funding. Tracking domestic spending on $\mathrm{RMNCH}$ will be critical and is improving based on the System of National Health Accounts (SHA) 2011. ${ }^{44} 4546$ WHO now hosts more than 30 SHA-based RMNCH health accounts ${ }^{47}$, and 12 countries have produced full disease breakdowns. ${ }^{48}$ It is however too early to gauge the big picture on trends in domestic spending for $\mathrm{RMNCH}$ or adolescent health. As of now, there are only limited recent and comparable data on catastrophic health spending for Countdown countries. Out-of-pocket expenditures tend to be high, exceeding $40 \%$ of total health expenditure in more than half of Countdown countries, and only 12 countries reported out-of-pocket expenditures below $20 \%$.

Comparable data on health service inputs such as infrastructure, supply systems and the health workforce that allow tracking over time are still limited. The latest WHO country data show continued low density of doctors, nurses and midwives in most Countdown countries. Only one quarter of the 81 countries have densities above 23 doctors, nurses and midwives per 10,000 population, a threshold used as a minimum required for high coverage of essential health interventions. ${ }^{49}$ The national 
availability of emergency obstetric care (EmOC) (expressed as a percentage of the minimum acceptable number of EmOC facilities which is at least five EmOC facilities per 500,000 people including one comprehensive and four basic emergency obstetric facilities ${ }^{50}$ ) was low in 30 countries with data from 2010 forward (median EmOC availability 40\%, range 13\% to 93\%). The poor availability of essential diagnostics and medicines observed in facility surveys is evidence of major deficiencies in country supply chain systems, even though the availability of supplies for RMNCH tends to be better than, for instance, for noncommunicable diseases. ${ }^{51}$

The centrality of UHC, as part of the SDG agenda and country strategies, has multiple implications for $\mathrm{RMNCH}$. The UHC prerogative means that health care packages designed for women, children and adolescent girls must be inclusive of curative, preventive and promotive services within a supportive legislative environment. Family planning is not included in health insurance plans in many countries, for example, yet access to family planning is critical for women, including adolescent girls, to be able to exercise their sexual and reproductive rights, and to experience better health outcomes. Decisions regarding what services are included in insurance plans and other health care delivery strategies require political engagement and alliances to ensure prioritization and visibility for RMNCH. ${ }^{52} 53$

Coverage in the UHC context relies on the availability and appropriate use of services that are of sufficient quality (Panel 2). Efforts to increase facility births will not lead to the expected gains in maternal and newborn health unless the quality of care in these facilities is adequate. These problems range from a lack of consistent supplies and equipment at health facilities, insufficient referral systems, inadequate training and supervision of health workers, to lack of respectful maternity care. Harmful practices are another reflection of poor quality of care and can be inadvertently incentivized by UHC financing strategies, such as the inappropriate use of antibiotics, ${ }^{54}$ caesarean sections ${ }^{55}$ or hysterectomies. $^{56}$

\section{Universal coverage for RMNCH interventions: still much to dol}

Three main conclusions emerge from our analysis of coverage, equity and drivers of RMNCH in the 81 Countdown countries. First, strong progress in the coverage of many essential RMNCH interventions was made during the past decade, but many countries are still a long way from universal coverage for most essential interventions. Moreover, there is growing evidence of the limited quality of services, due to lack of basic inputs such as medicines and trained health workers, thus limiting the potential impact on RMNCH outcomes. Second, inequalities in coverage between the poorest and the richest can be reduced to almost none, as shown by several countries. Within-country inequalities in coverage are reducing in most countries, but the pace is too slow. In several countries, significant poor-rich, urban-rural or geographical gaps persist for most RMNCH indicators.

Third, context matters for RMNCH. This includes the strength of health systems where major progress and shifts are needed in terms of policies and strategies (e.g. to promote inclusiveness and effectiveness), governance (e.g., to develop integrated and intersectoral approaches, and strengthen partnership with and regulation of the private sector etc.), financing (e.g., shift to greater reliance on domestic resources while protecting ODA flows for women's, children's and adolescents' health, ensure financial protection against catastrophic health spending), and health services delivery and systems (e.g., stronger health workforce, reliable supply chain system, good quality of services etc.). In addition, the increasing numbers of women, children, and adolescents in countries affected by conflict or other humanitarian emergencies need special attention, and countries need better data to guide their actions under these circumstances. Efforts are needed to further refine a theory of change on how broader 
determinants operate at both micro- and macro-levels in countries to impact RMNCH, and to develop associated multi-sectoral strategies to address them.

These findings demonstrate the need for countries to set medium-term coverage targets such as for 2020 and 2025 for selected indicators of the continuum of care, including an inequality dimension, to closely monitor progress towards UHC and the 2030 SDG targets related to RMNCH. Efforts to achieve the goal of reaching all women, children and adolescents should also be underpinned by better monitoring of the quality of services, greater use of health facility data for local action, special attention to the numbers of individuals not reached, simple understandable indexes such as the $\mathrm{CCl}$, and use of tools that link coverage data to lives saved and resource allocation. ${ }^{57} 58$

\section{Addressing the measurement and monitoring gaps}

An important limitation of our analysis of progress is the limited availability of recent empirical data on key indicators and inequality dimensions. Despite major improvements in data collection, there are not enough recent data points to assess whether the rate of improvement in survival or program performance observed during the MDG era is accelerating or not. Countdown makes only limited use of predictions and aims as much as possible "to let the country data speak", after adjustments for known biases as required. This implies that time periods rather than individual years are used to assess trends, with some variability between countries in terms of when the data were collected. Our analyses are also limited by the depth of information currently available on critical topics such as RMNCH coverage in conflict settings, quality of care for essential interventions, and subnational data on, for instance, health service inputs. Further work is ongoing to address these measurement gaps, both within and outside Countdown.

Better data are needed to track progress, inform programs and ensure accountability at national and local levels. The preferred way to obtain better data on mortality and causes of death is through sample registration systems which should eventually lead to complete civil registration and vital statistics systems. ${ }^{59}{ }^{60}$ Collecting high quality population data on stillbirths and early neonatal deaths, and related interventions around the time of childbirth including measures of the quality of care, often requires special efforts such as longitudinal studies of pregnant women. Population-based surveys must be conducted on a regular basis, as key sources of coverage data that can be disaggregated by multiple demographic, socioeconomic and geographic dimensions. Research is needed to develop and validate more indicators that capture the quality of care through surveys. ${ }^{61}{ }^{62}$ Increasing the sample size of surveys to allow better geographical disaggregation, as well as investing in the quality and coverage of administrative data, are essential for improving targeting of interventions to women, children, and adolescents from deprived areas. Health facility data, including routine reporting systems and facility surveys, can be used to improve monitoring of RMNCH indicators at local levels, provided completeness and accuracy of reporting by facilities is good. ${ }^{63}$ Linking of population and health facility surveys is at present the best way to measure access to and quality of specific services. Special studies are needed for determining how best to identify and reach underserved groups, to ascertain the quality of care and how to improve it, on reaching women and children with services in conflict situations, and to better understand the role of governance processes and legislative frameworks in improving RMNCH.

\section{Transforming the Countdown}

The SDGs call for a comprehensive and integrated health agenda, with UHC at the center of the health goal. The Every Woman Every Child Global Strategy for Women's, Children's and Adolescents' Health translates the SDG framework into a comprehensive "survive - thrive - transform" framework that goes well beyond $\mathrm{RMNCH} .{ }^{13}$ Countdown is responding to this new agenda in multiple ways, while preserving 
its core features (summarized in panel 4). Countdown will continue to publish independent comprehensive analyses of progress towards the RMNCH-related SDGs with a focus on coverage, equity and the drivers of coverage of cost-effective interventions addressing the main causes of maternal, neonatal and child deaths. This will include Countdown publications, as well as analytical inputs to the monitoring of progress and accountability related to the Every Woman Every Child Global Strategy for Women, Children's and Adolescents' Health 2016-2030, the analyses of the Independent Accountability Panel, and global efforts to monitor nutrition, and other priority areas.

Countdown is also investing in improving the measurement and analysis of intervention coverage, quality of care, nutrition, equity and key drivers of coverage, such as governance and financing, and RMNCH in conflict settings. These efforts will also include adolescent health, working with the Lancet Commission on Adolescent Health, with an initial focus on sexual and reproductive health, and early childhood development. Finally, Countdown is focusing on strengthening regional and country analytical capacity to improve monitoring and accountability for women's, children's and adolescents' health. We are responding to the demand for greater country capacity and evidence for action by working with country public health institutions and ministries of health through regional initiatives. Such initiatives are underway in Latin America and the Caribbean, West and Central Africa, and Eastern and Southern Africa, with leadership by regional institutions, close collaboration with UN agencies and the Health Data Collaborative. In addition, Countdown is continuing its engagement in country-specific analyses in close collaboration with country institutions, including for countries affected by conflict. It will be critical that global initiatives, notably GFF, GAVI and Global Fund, align their financing and implementation efforts behind these efforts to strengthening country analytical capacity.

This first Countdown global analysis in the SDG era shows both how we will continue to address the $\mathrm{RMNCH}$ and nutrition agenda in the 81 highest mortality countries and how we have begun to address the broader agenda of women's, children's and adolescents' health in the context of universal health coverage. RMNCH should capitalise on the opportunities provided by the SDGs. This analysis presents compelling evidence of progress as well as major persistent gaps and inequalities in the coverage of essential RMNCH interventions, justifying a continued prioritization of RMNCH within the context of UHC and the SDGs with their challenging 2030 targets. At the same time, a broader and more integrated approach is needed as countries face a much wider range of challenges for improving women's, children's and adolescents' health and nutrition. Countdown to 2030 is a unique global platform that can help address these challenges through fostering collaboration between multiple constituencies in multiple subject areas, and through focusing on tracking progress, improving measurement, and strengthening country capacity for evidence generation and use. 


\section{List of tables and figures}

Table 1: Coverage of RMNCH interventions along the continuum of care in 81 Countdown countries based from surveys 2012 or later, ranked by the Composite Coverage Index, data.

Table 2. Changes in national coverage of Countdown interventions along the continuum of care from 2005-2011 and 2012-2017 for countries with available data in both periods, and proportion of the gap closed (\%) over the two time periods

Table 3. CCl according to place of residence, woman's age and education and wealth quintiles in Countdown countries with data since 2005.

Figure 1: Average annual rate of decline for under-five and neonatal mortality levels, stillbirth rates and maternal mortality ratio during 2000-2015 (estimated) and 2015-2030 (projected to reach SDG 2030 target), country median for the 50 highest mortality Countdown countries.

Figure 2. Trends in stunting prevalence among children under five years of age in the poorest and richest wealth quintile of the population in 53 Countdown countries with available data between 1993 and 2015 (weighted analysis for population of children under five).

Figure 3: Coverage of interventions across the continuum of care, Countdown countries with available data, 2005-2010 and 2011-2017.

Figure 4. Countdown countries ranked according to the degree of absolute inequality (brown line) in the composite coverage index $(\mathrm{CCl})$, with coverage rates in the poorest and richest wealth quintiles (equiplots), countries with data since 2005.

Figure $5 . \mathrm{CCl}$ by region in selected Countdown countries with wide and narrow subnational geographic inequalities.

Figure $6 . \mathrm{CCl}$ trends by wealth (poorest and richest quintiles) in countries with two or more surveys between 1993 and 2015, according to country income groupings.

Figure 7 Panel 3. CCl according to political stability/ absence of violence, 59 Countdown countries. * 


\section{Panel 1: Millions of women and children not reached with life saving interventions}

The coverage levels (Table 1, Figure 3) translate into large absolute numbers of women and children in the 81 Countdown countries who were not reached with needed interventions in 2015 (Appendix Panel 1 provides details on the method):

- 140 million women of reproductive ages, and in a union (marriage or long-term cohabiting partnership), were not reached with modern methods of family planning

- 28 million births occurred without a skilled attendant

- 17 million children did not receive three doses of pentavalent vaccine.

- 12 million children under 5 with symptoms of acute lower respiratory tract illness were not taken to a health facility

- 33 million children under 5 with diarrhoea did not receive oral rehydration salts solution.

These numbers are a poignant reminder of the steep climb ahead to reaching universal coverage for essential interventions in the countries.

\section{Panel 2: Major gaps in the quality of care}

Many of the coverage indicators tracked by Countdown and routinely monitored by countries are indicative of contact with health services, but they tell us little about the quality of care received. ${ }^{62}$ Without an adequate level of quality, interventions are unlikely to result in expected health improvements. ${ }^{64}$ An increasing number of studies measure essential inputs to health care (such as diagnostics, medicines, other supplies and equipment), on the contents of care provided (process of care provision from health providers) and outcomes and impact (effective coverage) (Appendix Panel 2). Household surveys can provide data on health care needs, utilization of health services and content of care and health facility surveys may capture health facility inputs or readiness and process indicators through direct observation of clinical visits or exit interviews. Linking these surveys for countries with both types of data in the same timeframe ${ }^{65}$ showed that major losses in potential individual and population health gains are occurring in every service area examined including family planning services, ${ }^{66}$ antenatal care, ${ }^{67}$ obstetric care, ${ }^{68} 6970$ and newborn care ${ }^{71}$.

Essential interventions to be delivered during antenatal care, for example, are often provided inconsistently, ${ }^{72}$ basic resources needed for safe and effective delivery care are often absent, ${ }^{73} 74$ opportunities for immunization are missed $^{75}$ and misdiagnosis and incorrect treatment of childhood illnesses are common. ${ }^{76} 77$ Gaps between coverage levels of receipt of antenatal care (four or more visits) and coverage levels adjusted to take into consideration available service inputs can be as large as 30-45 percentage points. ${ }^{6727879}$ Gaps in process-adjusted coverage for antenatal care are even larger at around 50\% (Appendix Panel 2). Further work is needed to measure the impact of quality gaps (due to inadequate inputs or provision/process of service delivery) on population health gains and to guide interventions to address these gaps. 


\section{Panel 3: Women and children in conflict settings}

The world has seen an upsurge in violent conflicts in recent years, with numbers of combat and civilian deaths rising since $2012 .^{80}$ This has led to an increase in forcibly displaced people to 65.6 million by the end of 2016, or just under $1 \%$ of the world's population, 22.5 million of whom were refugees ${ }^{81}$. The upsurge in violent conflicts in recent years is affecting RMNCH. Using battle-related deaths ${ }^{82}$ as an indicator of the existence and size of conflicts, 32 Countdown countries experienced at least one conflict during 2011-2016. Among those, 10 Countdown countries are experiencing severe conflicts, defined as having at least 5,000 battle-related deaths during 2011-2016 and more than 100,000 refugees, asylum seekers and internally displaced persons in 2016: Afghanistan, Central African Republic, Democratic Republic of Congo, Iraq, Nigeria, Pakistan, Somalia, South Sudan, Sudan and Yemen. In addition, Syria, Libya and Ukraine, all three not part of the 81 Countdown countries, are classified as having severe conflicts. Women and children are increasingly affected by the changing nature of conflict from inter- to intra-state and from acute, time limited to longer term events. Conflicts now occur more frequently in densely populated urban areas with much graver implications for civilians. Most refugees and internally displaced persons are women and children. According to available data on 24.4 million displaced persons in $2016,16 \%$ were children under $5,37 \%$ children $5-17$ years of age, and $23 \%$ were women 18 years and older. ${ }^{83}$

There are very few reliable statistics on deaths due to violence and warfare among women and children. The evidence of the impact of conflicts on disease burden and health service coverage is piecemeal, and is often dominated by data on conflict-affected populations in more stable settings such as refugee camps in protracted conflict settings, with often encouraging statistics compared to host populations. ${ }^{84}$ (e.g. on maternal mortality ${ }^{85}$, child malnutrition ${ }^{86}, \mathrm{MNCH}$ coverage ${ }^{87}{ }^{88}$ ). There is definite evidence of adverse consequences such as outbreaks of vaccine-preventable ${ }^{89}$ and diarrhoeal diseases ${ }^{90}$, increasing prevalence of acute malnutrition ${ }^{91}$ and mental health problems $\mathrm{s}^{92}$ in conflict settings. Women, including adolescent girls, are also at greater risk of becoming victims of sexual violence, commonly reported in almost all conflict settings ${ }^{93}$, with major consequences such as unwanted pregnancy, HIV infection and other sexual and reproductive health problems, as well as social problems such as stigmatization and exclusion by families and communities.

Recent Countdown studies in Afghanistan and Syria have shown, in spite of lack of comprehensive data from the most affected areas, adverse impact of the conflict on the coverage of essential RMNCH interventions. ${ }^{94} 95$ A macro-level analysis of the association between six dimensions of governance (government efficiency, control of corruption, political stability and absence of violence, regulatory quality, rule of law and voice and accountability) ${ }^{96}$ and composite coverage index (CCI) in 59 Countdown countries also showed that the strongest predictor of high and equitable coverage was political stability and absence of violence, even after statistical adjustment for the per capita gross domestic product, the Gini coefficient for income concentration and country's population and surface area (Figure 7). None of the other five dimensions of governance were associated with coverage after the statistical adjustment.

To help raise the visibility of the urgent need for more investments in $\mathrm{RMNCH}$ in conflict affected countries, Countdown to 2030 is working in partnership with other institutions to develop better ways of measuring and monitoring coverage of $\mathrm{RMNCH}$ interventions in conflict settings. 


\section{Panel 4: Countdown to 2030: priority areas of work}

- Publish independent high quality comprehensive analyses of progress towards the RMNCH-related SDGs with a focus on coverage and equity of the cost-effective interventions against the main causes of maternal and child deaths;

- Provide analytic inputs to the monitoring of progress and accountability related to the Every Woman Every Child Global Strategy for Women, Children's and Adolescents' Health 2016-2030, the Independent Accountability Panel, global efforts to monitor nutrition, adolescent health, early childhood development, and other global and regional reports;

- Improve the measurement of coverage of interventions, including more and better disaggregation of available data and quality of care;

- Improve the measurement and analyses of key drivers of intervention coverage, such as governance, policy implementation, civil society representation, and conflict settings;

- Strengthen regional and country analytical capacity to improve information for better accountability for women's, children's and adolescents' health in the context of the SDGs and UHC. 


\section{References}

${ }^{1}$ UN Interagency Group on Child Mortality Estimates (IGME). Levels \& trends in child mortality: report 2015. UNICEF, New York. September 2015.

${ }^{2}$ World Health Organization. Trends in maternal mortality: 1990 to 2015: estimates by WHO, UNICEF, UNFPA, World Bank Group and the United Nations Population Division. WHO, Geneva. September 2015.

${ }^{3}$ GBD 2015 Child Mortality Collaborators. Global, regional, national, and selected subnational levels of stillbirths, neonatal, infant, and under-5 mortality, 1980-2015: a systematic analysis for the Global Burden of Disease Study 2015. Lancet 2016, 388(10053): 1725-1774.

${ }^{4}$ GBD 2015 Maternal Mortality Collaborators. Global, regional, and national levels of maternal mortality, 19902015: a systematic analysis for the Global Burden of Disease Study 2015" Lancet 2016, 388(10053): 1775-1812

${ }^{5}$ WHO. From Millennium Development goals to Sustainable Development Goals: the situation and trends in 2015. Geneva: December 2015.

${ }^{6}$ Victora CG, Requejo JH, Barros AJ, et al. Countdown to 2015: a decade of tracking progress for maternal, newborn, and child survival. Geneva. 2015. Lancet. 2016; 387(10032):2049-59.

${ }^{7}$ Kuruvilla S, Schweizer J, Bishai D et al. Success factors for reducing maternal and child mortality Bull World Health Organ 2014; 92: 533-544.

${ }^{8}$ El Arifeen S, Hill K, Ahsan KZ, Jamil K, Nahar Q, Streatfield PK. Maternal mortality in Bangladesh: a Countdown to 2015 country case study. Lancet. 2014; 384(9951): 1366-74.

${ }^{9}$ Huicho L, Segura ER, Huayanay-Espinoza CA, et al. on behalf of the Peru Countdown Country Case Study Working Group. Child health and nutrition in Peru within an antipoverty political agenda: a Countdown to 2015 country case study. Lancet Glob Health. 2016; 4: e414-26.

${ }^{10}$ Huicho L, Huayanay-Espinoza CA, Herrera-Perez E, et al. Factors behind the success story of under-five stunting in Peru: a district ecological multilevel analysis. BMC Pediatr 2017; 17: 29.

${ }^{11} \mathrm{Gao} \mathrm{Y}$, Zhou H, Singh NS, et al. Progress and challenges in maternal health in western China: a Countdown to 2015 national case study. Lancet Glob Health 2017;5(5): e523-e536.

12 United Nations. Transforming our world: the 2030 Agenda for Sustainable Development. Resolution A/RES/70/1. Adopted September 2015.

${ }^{13}$ United Nations. The global strategy for women's, children's and adolescents' health (2016-2030): survive, thrive, transform. New York (NY): United Nations, Every Woman Every Child. 2015.

${ }^{14}$ Temmerman M, Khosla R, Bhutta Z, Bustreo F. Towards a new Global Strategy for Women's, Children's and Adolescent Health. BMJ 2015; 351: S1-70.

${ }^{15}$ Claeson M. The Global Financing Facility-towards a new way of financing for development. Lancet 2017, 389: 1588-1592.

${ }^{16}$ Bhutta ZA, Chopra M. Moving ahead: what will a renewed Countdown to 2030 for Women and Children look like? Lancet 2016; 387: 2016; 387: 2060-6.

${ }^{17}$ United Nations, Department of Economic and Social Affairs, Population Division (2017). World Population Prospects: The 2017 Revision, DVD Edition.

${ }^{18}$ UN Interagency Group on Child Mortality Estimates (IGME). Levels \& trends in child mortality: report 2016. UNICEF, New York: 2017.

${ }^{19}$ Blencowe H, Cousens S, Jassir FB, et al, for The Lancet Stillbirth Epidemiology Investigator Group. National, regional, and worldwide estimates of stillbirth rates in 2015, with trends from 2000: a systematic analysis. Lancet Glob Health 2016; published online Jan 18.

${ }^{20}$ WHO, UNICEF. Every Newborn: an action plan to end preventable deaths. Geneva: World Health Organization, 2014.

${ }^{21}$ Alkema L, Chou D, Hogan D et al. Global, regional, and national levels and trends in maternal mortality between 1990 and 2015, with scenario-based projections to 2030: a systematic analysis by the UN Maternal Mortality Estimation Inter-Agency Group. Lancet 2016; 387: 462-74.

${ }^{22}$ UN Interagency Group on Child Mortality Estimates (IGME). Levels \& trends in child mortality: report 2016. UNICEF, New York: 2017.

${ }^{23}$ Liu L, Oza S, Hogan D, et al. Global, regional, and national causes of under-5 mortality in 2000-15: an updated systematic analysis with implications for the Sustainable Development Goals. Lancet 2016; 388: 3027-3035. 
${ }^{24}$ GBD 2016 Causes of Death Collaborators. Global, regional, and national age-sex specific mortality for 264 causes of death, 1980-2016: a systematic analysis for the Global Burden of Disease Study 2016. Lancet 2017; 390: 1151210.

${ }^{25}$ Say L, Chou D, Gemmill A. Global causes of maternal death: a WHO systematic analysis. Lancet Glob Health 2014; 2(6): e323-33.

${ }^{26}$ GBD 2016 Causes of Death Collaborators. Global, regional, and national age-sex specific mortality for 264 causes of death, 1980-2016: a systematic analysis for the Global Burden of Disease Study 2016. Lancet 2017; 390: 1151210

${ }^{27}$ Black RE, Victora CG, Walker SP et al. Maternal and child undernutrition and overweight in low-income and middle-income countries. Lancet 2013; 382: 427-51.

${ }^{28}$ Lu C, Black M, Richter LM. Risk of poor development in young children in low-income and middle-income countries: an estimation and analysis at the global, regional, and country level. Lancet Global Health,2017, 4, No. 12, e916-e922.

${ }^{29}$ UNICEF, WHO and World Bank Group. Levels and trends in child malnutrition. Joint Child Malnutrition Estimate. Key findings of the 2017 edition. Geneva: 2017. http://www.who.int/nutgrowthdb/estimates2016/en/

${ }^{30}$ Wehrmeister FC, Restrepo-Mendez MC, Franca GV, Victora CG, Barros AJ. Summary indices for monitoring universal coverage in maternal and child health care. Bull World Health Organ. 2016; 94(12): 903-912.

${ }^{31}$ Rutstein SO, Johnson K. The DHS wealth index: comparative reports no 6 . Calverton, Maryland: ORC Macro; 2004.

${ }^{32}$ Barros AJD, Victora CG. Measuring Coverage in MNCH: Determining and interpreting inequalities in coverage of maternal, newborn, and child health interventions. PLoS Med 2016, 10(5): 119-127.

${ }^{33}$ Ewerling F, Lynch JW, Victora CG, van Eerdewijk A, Tyszler M, Barros AJD. The SWPER index for women's empowerment in Africa: development and validation of an index based on survey data. Lancet Glob Health 2017; 5: e916-23

${ }^{34}$ International Labour Organization. C183 - Maternity Protection Convention, 2000 (No. 183). Convention concerning the revision of the Maternity Protection Convention (Revised), 1952 (Entry into force: 07 Feb 2002) Adoption: Geneva, 88th ILC session (15 Jun 2000) - Status: Up-to-date instrument (Technical Convention).

${ }^{35}$ Countdown to 2030. Tracking progress towards universal coverage for reproductive, maternal, newborn and child health. 2017 report. UNICEF and WHO. Geneva. 2017.

${ }^{36}$ United Nations Population Division policy database. https://esa.un.org/poppolicy/wpp datasets.aspx. (Accessed October 11, 2017).

${ }^{37}$ Ganatra B, Gerdts C, Rossier C, et al. Global, regional, and subregional classification of abortions by safety, 201014: estimates from a Bayesian hierarchical model. Lancet Published Online September 27, 2017

http://dx.doi.org/10.1016/ S0140-6736(17)31794-4.

${ }^{38}$ Buse K, Mays N, Walt G. Making Health Policy. $2^{\text {nd }}$ ed. Open University Press. 2012

${ }^{39}$ Walt G, Gilson L. Reforming the health sector in developing countries: the central role of policy analysis. Health Policy Plan 1994;9(4):353-70.

${ }^{40}$ Shiffman J, Smith S. Generation of political priority for global health initiatives: a framework and case study of maternal mortality. Lancet 2007;370(9595):1370-9.

${ }^{41}$ George A, Rodríguez DC, Rasanathan K, Brandes N, Bennett S. iCCM policy analysis: strategic contributions to understanding its character, design and scale up in sub-Saharan Africa. Health Policy Plan 2015;30 Suppl 2:ii3-ii11.

${ }^{42}$ Singh NS, Huicho L, Afnan-Holmes H, et al. on behalf of the Countdown to 2015 Health Systems and Policies Technical Working Group. Countdown to 2015 country case studies: systematic tools to address the "black box" of health systems and policy assessment. BMC Public Health. 2016 Sep 12;16 Suppl 2:790. doi: 10.1186/s12889-0163402-5.

${ }^{43}$ Grollman C, Arregoces L, Martínez-Álvarez M, Pitt C, Mills A, Borghi J. 11 years of tracking aid to reproductive, maternal, newborn, and child health: estimates and analysis for 2003-13 from the Countdown to 2015 Lancet Glob Health 2017; 5: e104-14.

${ }^{44}$ Cogswell H, Connor C, Dereje T, Kaplan A, Nakhimovsky S. 2013. System of Health Accounts 2011: What is SHA 2011 and How Are SHA 2011 Data Produced and Used? Bethesda, MD: Health Finance \& Governance project, Abt 
Associates Inc. Available at: https://www.hfgproject.org/wp-content/uploads/2014/03/SHA-Brief.pdf (Accessed June 1, 2017).

${ }^{45}$ OECD, Eurostat, WHO. 2011. A System of Health Accounts: 2011 Edition. OECD, Eurostat, and WHO. http://www.who.int/health-accounts/methodology/sha2011.pdf (Accessed June 1, 2017)

${ }^{46}$ Black RE, Levin C, Walker N, Chou D, Temmerman M for the DCP3 RMNCH authors group. Reproductive, maternal, newborn, and child health: key messages from Disease Control Priorities 3rd Edition. Lancet 2016; 388: 2811-2824.

${ }^{47}$ WHO. Global Health Data Exchange. WHO; Geneva, Switzerland. Available at: http://apps.who.int/nha/database/DocumentationCentre/Index/en (Accessed June 1, 2017)

${ }^{48}$ Cogswell H, Connor C, Dereje T, Kaplan A, Nakhimovsky S. 2013. System of Health Accounts 2011: What is SHA 2011 and How Are SHA 2011 Data Produced and Used? Bethesda, MD: Health Finance \& Governance project, Abt Associates Inc. Available at: https://www.hfgproject.org/wp-content/uploads/2014/03/SHA-Brief.pdf (Accessed June 1, 2017).

${ }^{49}$ Pozo-Martin F, Nove A, Lopes SC et al. Health workforce metrics pre- and post-2015: a stimulus to public policy and planning. Hum Resour Health. 2017;15(1):14.

${ }^{50}$ World Health Organization, UNFPA, UNICEF and Mailman School of Public Health. Averting Maternal Death and Disability (AMDD). Monitoring emergency obstetric care: A Handbook. Geneva. 2009

${ }^{51}$ O'Neill K, Takane M, Sheffel A, Abou-Zahr C, Boerma T. Monitoring service delivery for universal health coverage: the Service Availability and Readiness Assessment. Bull World Health Organ. 2013;91(12):923-31.

${ }^{52}$ Shiffman J. Knowledge, moral claims and the exercise of power in global health. Int J Health Policy Manag. 2014 Nov 8;3(6):297-9.

${ }^{53}$ Smith SL, Shiffman J, Kazembe A. Generating political priority for newborn survival in three low-income countries. Glob Public Health. 2014;9(5):538-54.

${ }^{54}$ LeFevre AE, Mohan D, Mazumder S, et al. Diarrhea no more: does zinc help the poor? Evidence on the effectiveness of programmatic efforts to reach poorest in delivering zinc and ORS at scale in UP and Gujarat, India. J Glob Health. 2016 Dec;6(2):021001.

${ }^{55}$ Zhao Y, Zhang J, Zamora J, et al. Increases in Caesarean Delivery Rates and Change of Perinatal Outcomes in Lowand Middle-Income Countries: A Hospital-Level Analysis of Two WHO Surveys. Paediatr Perinat Epidemiol. 2017 Jul;31(4):251-262.

${ }^{56}$ Desai S, Campbell OM, Sinha T, Mahal A, Cousens S. Incidence and determinants of hysterectomy in a lowincome setting in Gujarat, India. Health Policy Plan. 2017; 32(1): 68-78.

57 Johns Hopkins University. Lives saved tool (iST). http://www.livessavedtool.org/ (accessed 10 October 2017)

58 UNICEF. Equitable strategies to save lives (EQUIST). https://www.unicef.org/health/files/EQUIST flyer English.pdf (accessed 10 October 2017)

${ }^{59}$ Hill K, Lopez AD, Shibuya K, Jha P on behalf of the Monitoring of Vital Events (MoVE) writing group. Who Counts? 3. Interim measures for meeting needs for health sector data: births, deaths, and causes of death. Lancet 2007, 370(9600): 1726-1735.

${ }^{60}$ WHO Improving Mortality Statistics through Civil Registration and Vital Statistics Systems: Strategies for country and partner support. Outcome of a technical meeting Geneva, 4-5 November 2014.

http://www.who.int/healthinfo/civil_registration/CRVS_MortalityStats_Guidance_Nov2014.pdf?ua=1

${ }^{61}$ Grove J, Claeson M, Bryce J et al. Maternal, newborn, and child health and the Sustainable Development Goals--a call for sustained and improved measurement. Lancet 2015, 386(10003): 1511-1514.

${ }^{62}$ Marchant T, Bryce J, Victora C, Moran AC, Claeson M, Requejo J, et al. Improved measurement for mothers, newborns and children in the era of the Sustainable Development Goals. J Glob Health. 2016; 6(1): 010506.

${ }^{63}$ Maina I, Wanjala P, Soti D, Kipruto H, Droti B, Boerma T. Using health-facility data to assess subnational coverage of maternal and child health indicators, Kenya. Bull World Health Organ 2017; 95: 683-694.

${ }^{64}$ Tunçalp Ö, Were WM, MacLennan C, Oladapo OT, Gülmezoglu AM, Bahl R, Daelmans B, Mathai M, Say L, Kristensen F, Temmerman M, Bustreo F. Quality of care for pregnant women and newborns - the WHO vision. BJOG 2015; 122: 1045-1049.

${ }^{65}$ Do M, Micah A, Brondi L, et al. Linking household and facility data for better coverage measures in reproductive, maternal, newborn, and child health care: systematic review. J Glob Health. 2016; 6: 020501. 
${ }^{66}$ Tessema GA, Streak Gomersall J, Mahmood MA, Laurence CO. Factors Determining Quality of Care in Family Planning Services in Africa: A Systematic Review of Mixed Evidence. PLoS One. 2016;11(11): e0165627.

${ }^{67}$ Marchant T, Tilley-Gyado RD, Tessema T, et al. Adding Content to Contacts: Measurement of High Quality Contacts for Maternal and Newborn Health in Ethiopia, North East Nigeria, and Uttar Pradesh, India. PLoS ONE 10(5): e0126840.

${ }^{68}$ Sharma G, Mathai M, Dickson E, et al. Quality care during labour and birth: a multicountry analysis of health system bottlenecks and potential solutions. BMC Pregnancy and Childbirth 2015, 15(Suppl 2): S2.

${ }^{69}$ Chaturvedi S, Randive B, Diwan V, De Costa A. Quality of obstetric referral services in India's JSY cash transfer programme for institutional births: a study from Madhya Pradesh province. PLoS One 2014;9:e96773.

${ }^{70}$ Leslie HH, Fink G, Nsona H, Kruk ME. Obstetric Facility Quality and Newborn Mortality in Malawi: A CrossSectional Study. PLoS Med 2016;13:e1002151.

${ }^{71}$ Dickson KE, Kinne MV, Moxon SG. Scaling up quality care for mothers and newborns around the time of birth: an overview of methods and analyses of intervention-specific bottlenecks and solutions. BMC Pregnancy and Childbirth 2015, 15 (Suppl 2):S1

${ }^{72}$ Hodgins S, D'Agostino A. The quality-coverage gap in antenatal care: toward better measurement of effective coverage. Global health, science and practice. 2014;2(2):173-81.

${ }^{73}$ Kruk ME, Leslie HH, Verguet S, Mbaruku GM, Adanu RMK, Langer A. Quality of basic maternal care functions in health facilities of five African countries: an analysis of national health system surveys. The Lancet Global Health. 2016.

${ }^{74}$ Sharma J, Leslie HH, Kundu F, Kruk ME. Poor Quality for Poor Women? Inequities in the Quality of Antenatal and Delivery Care in Kenya. PLOS ONE. 2017;12(1):e0171236.

${ }^{75}$ Restrepo-Méndez MC, Barros AJ, Wong KL. Missed opportunities in full immunization coverage: findings from low- and lower-middle-income countries. Glob Health Action. 2016 Jan;9(1):30963. doi: 10.3402/gha.v9.30963.

${ }^{76}$ Mohanan M, Vera-Hernandez M, Das V, Giardili S, Goldhaber-Fiebert JD, Rabin TL, et al. The know-do gap in quality of health care for childhood diarrhea and pneumonia in rural India. JAMA pediatrics. 2015;169(4):349-57. ${ }_{77}$ Carter ED. Measuring Child Health Coverage: Validation of Maternal-Reported Care-seeking and New Methods for Estimating Coverage of Appropriate Management of Childhood Illness: Johns Hopkins University School of Public Health; 2017.

${ }^{78}$ Kanyangarara M, Munos MK, Walker N. 2017. Quality of antenatal care service provision in health facilities across Sub-Saharan Africa: Evidence from nationally representative health facility assessment, Journal of Global Health, In Press.

${ }^{79}$ Blanc AK, Warren C, McCarthy KJ, Kimani J, Ndwiga C, RamaRao S. 2016. Assessing the validity of indicators of the quality of maternal and newborn health care in Kenya. Journal of Global Health. June $2016 \bullet$ Vol. 6 No. $1 \bullet$ 010405 doi: $10.7189 /$ jogh.06.010405.

${ }^{80}$ Gates S, Nygård HM, Strand H, Urdal H. Trends in Armed Conflict 1946-2014. Peace Resarch Institute Oslo (PRIO). 2016.

${ }^{81}$ UNHCR. Global trends: forced displacement in 2016. Geneva. 2017. http://www.unhcr.org/5943e8a34

82 Uppsala Conflict Data Program (http://ucdp.uu.se/\#/encyclopedia.

83 UNHCR. Global Trends: Forced Displacement in 2016 - Annex Tables (Table 13). Available

at: http://www.unhcr.org/globaltrends2016/\#

${ }^{84}$ Checchi F, Warsame A, Treacy-Wong V, Polonsky J, van Ommeren M, Prudhon C. Public health information in crisis-affected populations: a review of methods and their use for advocacy and action. June 8, 2017

http://dx.doi.org/10.1016/ S0140-6736(17)30702-X.

${ }^{85}$ Hynes, M., et al. A study of refugee maternal mortality in 10 countries, 2008-2010. Int Perspect Sex Reprod Health 2012, 38(4): 205-213

${ }^{86}$ Mason JB, White JM, Heron L, Carter J, Wilkinson C, Spiegel P. Child acute malnutrition and mortality in populations affected by displacement in the Horn of Africa, 1997-2009. Int J Environ Res Public Health. 2012; 9(3): 791-806.

${ }^{87}$ Whitmill, J., Blanton, C., Doraiswamy, S. et al. Retrospective analysis of reproductive health indicators in the United Nations High Commissioner for Refugees post-emergency camps 2007-2013. Conflict and Health 2016; 10 : 3. DOI 10.1186/s13031-016-0069-6 
${ }^{88}$ Hynes, M., et al. Reproductive health indicators and outcomes among refugee and internally displaced persons in postemergency phase camps. Jama 2002, 288(5): 595-603.

${ }^{89}$ Lam, E., et al. Vaccine-preventable diseases in humanitarian emergencies among refugee and internallydisplaced populations. Hum Vaccin Immunother 2015,11(11): 2627-2636.

${ }^{90}$ Ramesh A, Blanchet K, Ensink JHJ, Roberts B. Evidence on the Effectiveness of Water, Sanitation, and Hygiene (WASH) Interventions on Health Outcomes in Humanitarian Crises: A Systematic Review. PLoS ONE, 2015, 10(9): e0124688.

${ }^{91}$ Bahwere P. Severe acute malnutrition during emergencies: Burden, management, and gaps. Food and Nutrition Bulletin 2014; 35(2).

92 Foster, H. and J. Brooks-Gunn. Children's exposure to community and war violence and mental health in four African countries. Soc Sci Med 2015, 146: 292-299.

${ }^{93}$ Stark L, Ager A. A systematic review of prevalence studies of gender-based violence in complex emergencies. Trauma Violence Abuse 2011; 12: 127-34.

${ }^{94}$ Akseer N, Salehi AS, Hossain MM, et al. Achieving maternal and child health gains in Afghanistan: a Countdown to 2015 country case study. Lancet Glob Health 2016; 4: e395-413

${ }^{95}$ DeJong, J., Ghattas, H., Bashour, H., et al. Reproductive, Maternal, Neonatal and Child Health in Conflict: A case study on Syria using Countdown indicators. BMJ Global Health 2017;2: e000302. doi:10.1136/bmjgh-2017-000302

${ }^{96}$ World Bank governance index. http://info.worldbank.org/governance/wgi/\#home 